\title{
Comparative Study of the Phytoprostane and Phytofuran Content of indica and japonica Rice (Oryza sativa L.) Flours
}

\author{
M. Pinciroli, ${ }^{\dagger}$ R. Domínguez-Perles, ${ }^{*}{ }^{\ddagger}$ A. Abellán, ${ }^{\ddagger}$ A. Guy, ${ }^{\S}$ T. Durand, ${ }^{\S}$ C. Oger, ${ }^{\S}$ J. M. Galano, ${ }^{\S}$ \\ F. Ferreres, ${ }^{\ddagger}$ and A. Gil-Izquierdo* ${ }^{*}$ \\ ${ }^{\dagger}$ Programa Arroz, Facultad de Ciencias Agrarias y Forestales Universidad Nacional de la Plata. Calle 60 y 119, 1900 La Plata, Buenos \\ Aires, Argentina \\ ${ }^{\ddagger}$ Research Group on Quality, Safety and Bioactivity of Plant Foods.Department of Food Science and Technology, CEBAS-CSIC, \\ Campus de Espinardo 25, 30100 Espinardo, Spain \\ ${ }^{\S}$ Institut des Biomolécules Max Mousseron (IBMM), UMR 5247, CNRS, University of Montpellier, ENSCM, 34090 Montpellier, \\ France
}

ABSTRACT: Phytoprostanes and phytofurans (PhytoPs and PhytoFs, respectively) are nonenzymatic lipid peroxidation products derived from $\alpha$-linolenic acid (C18:3 n-3), considered biomarkers of oxidative degradation in plant foods. The present work profiled these compounds in white and brown grain flours and rice bran from 14 rice cultivars of the subspecies indica and japonica by ultrahigh performance liquid chromatography coupled to electrospray ionization and triple quadrupole mass spectrometry. For PhytoPs, the average concentrations were higher in rice bran (0.01-9.35 $\mathrm{ng} \mathrm{g}^{-1}$ ) than in white and brown grain flours $\left(0.01-1.17 \mathrm{ng} \mathrm{g}^{-1}\right)$. In addition, the evaluation of rice flours for the occurrence PhytoFs evidenced average values $1.77,4.22$, and $10.30 \mathrm{ng} \mathrm{g}^{-1} \mathrm{dw}$ in rice bran, brown grain flour, and white grain flour, respectively. A significant correlation was observed between total and individual compounds. The concentrations retrieved suggest rice bran as a valuable source of PhytoPs and PhytoFs that should be considered in further studies on bioavailability and bioactivity of such compounds.

KEYWORDS: white rice flour, brown rice flour, rice bran, phytoprostanes, phytofurans, processing

\section{INTRODUCTION}

Plants and animals contain polyunsaturated fatty acids (PUFAs) in their membranes, which are responsible for modulating membrane fluidity and can be released and metabolized enzymatically to oxidized fatty acids, some of which act as defense signals in higher plants, in vivo (e.g., jasmonates or antimicrobial lipids). ${ }^{1}$ In addition to enzymatic oxidation, plant membranes (especially those rich in linolenate) are prone to nonenzymatic oxidation that gives rise to phytoprostanes (PhytoPs). These compounds represent a broad range of biologically active oxidized lipids that are generated as a consequence of redox unbalance and oxidative stress. The discovery of PhytoPs has focused the interest of the research community because of their structural analogy regarding well established animal mediators of biological reactions such as isoprostanes (IsoPs) and prostanoids (prostaglandins and thromboxanes), also generated by nonenzymatic free radical attack and cyclooxygenase action on arachidonic acid, respectively. ${ }^{2}$

The occurrence of PhytoPs and phytofurans (PhytoFs) in plant foods has been reported in the last two decades concerning a variety of matrices including vegetable oils, seeds, and nonedible plant materials such as melon leaves. ${ }^{3-8}$ These characterizations have provided important information on those matrices that seem to be the most relevant dietary sources of such compounds, their concentration being related to the level of $\alpha$-linolenic acid (C18:3 n-3, ALA). Besides the dietary interest in these foods and foodstuffs as sources of
PhytoPs and PhytoFs, the level of these compounds has been related to the plant's response to abiotic stress. ${ }^{5}$

Mammalian oxylipins, eicosanoids among others, are accepted to perform a wide range of functions in biological systems, from pernicious effects (platelet aggregation and vasoconstriction) to benefits related to the maintenance of the physiological-defensive balance. ${ }^{9}$ Mirroring these effects in human cells, PhytoPs have been related to anti-inflammatory properties and protection against neuronal lesions induced by pro-oxidant radicals. ${ }^{10}$ Apart from PhytoPs, under high oxygen tension, another cyclic structure of compounds referred to as PhytoFs is generated upon additional oxidation after the initial endoperoxide formation. ${ }^{11}$

Thus, though to date the biological benefits associated with the consumption of plant foods have been attributed to a wide variety of compounds described in such matrices, the new description of PhytoPs and PhytoFs allows us to envisage that, at least to some extent, these compounds could contribute to the healthy attributions of plant foods. In this sense, further research on bioavailability and biological activity of PhytoPs and PhytoFs in vivo is currently in progress, ${ }^{12}$ complementing the current trend on the evaluation of the value of PhytoPs and PhytoFs as markers of oxidation in foods. ${ }^{3}$ In this sense, to establish the actual interest of these compounds, first it should

Received: July 27, 2017

Revised: September 14, 2017

Accepted: September 20, 2017

Published: September 20, 2017 
Table 1. Climatic Conditions in the Experimental Field $\left(34^{\circ} 52^{\prime} \mathrm{S}, 57^{\circ} 57^{\prime} \mathrm{W}, 9.8 \mathrm{~m}\right.$ of Altitude) during the Rice Crop

\begin{tabular}{|c|c|c|c|c|c|c|c|}
\hline \multirow[b]{2}{*}{ Parameter } & \multicolumn{7}{|c|}{ month/year } \\
\hline & October/2015 & November/2015 & December/2015 & January/2016 & February/2016 & March/2016 & April/2016 \\
\hline$T_{\mathrm{m}}\left({ }^{\circ} \mathrm{C}\right)^{a}$ & 8.8 & 12.3 & 15.8 & 17.4 & 17.9 & 13.1 & 12.1 \\
\hline$T_{\mathrm{M}}\left({ }^{\circ} \mathrm{C}\right)^{b}$ & 18.7 & 23.4 & 28.0 & 28.9 & 29.8 & 24.6 & 19.7 \\
\hline $\mathrm{RH}(\%)^{c}$ & 72.0 & 72.0 & 57.0 & 69.0 & 72.0 & 69.0 & 61.0 \\
\hline $\mathrm{RR}(\mathrm{mm})^{d}$ & 67.6 & 130.0 & 36.6 & 67.4 & 72.0 & 104.6 & 160.6 \\
\hline
\end{tabular}

be established rationally their occurrence in the wide variety of foods comprising humans' diet.

Despite the interest in these molecules as potential bioactive compounds contributing to the healthy attributions of plant foods, to date there is not enough evidence on their bioavailability, ${ }^{13,14}$ and even less on the scope of their biological power, which has been mainly addressed to their capacity to polarize the immune response to a Th2 type. ${ }^{15}$

However, almost 20 years after the first description, ${ }^{16}$ the scientific literature on PhytoPs and PhytoFs has been mainly focused on the evaluation of their occurrence in edible and nonedible higher plant species and manufactured products. $^{2,4-8,17}$ In this frame, rice (Oryza sativa L.) is one of the most important food crops around the world, being the staple food for more than half of the world's population. ${ }^{18}$ Subspecies indica and japonica rice are the two main subspecies grown in tropical/subtropical environments and under mild climatic conditions, respectively. These subspecies differ clearly in morphological, agronomic, physiological, and biochemical features, as well as in yield, quality, and resistance to stress. ${ }^{19}$ In addition, indica and japonica subspecies also diverge regarding their content of $\alpha$-linolenic acid, precursor of PhytoPs and PhytoFs, which influences the distinct concentration of such compounds in different plant foods and foodstuffs. ${ }^{4}$

The rice plant is threshed to produce paddy rice, which is defatted to obtain brown rice. Then, brown rice is separated by a machine and polished in bran (external parts of the grain including pericarp, tegmen, aleurone layer, and embryo), and polished rice (milled rice or white rice) involves the internal parts of the grain, corresponding substantially to endosperm. In these matrices, lipids are mainly concentrated in the series of rice bran $(22.5 \%)$, brown rice $(2.3 \%)$, and white rice $(0.8 \%){ }^{20}$

To date, their value as indicators of the quality of rice based foods and foodstuffs given their conditions of metabolites of oxidation of fatty acids has been already demonstrated; however, to gain further insight on the biological interest of these compounds as markers in vitro as mediators of metabolic pathways that could be of interest for health requires accurate determinations of their occurrence in plant foods. Hence, the objective of the present work was to assess, for the first time, different types of rice flours obtained from white and brown grains and diverse rice brans of different indica and japonica cultivars on their concentration of PhytoPs and PhytoFs by UHPLC-ESI-QqQ-MS/MS. The value of these matrices as a dietary source of these largely unknown oxylipins needs to be addressed in order to plan rationally nutritional trials devoted to shed some light on their actual biological activity.

\section{MATERIALS AND METHODS}

Chemicals and Reagents. The PhytoPs (9- $\mathrm{F}_{1 \mathrm{t}}$-PhytoP (PP1); ent-16- $\mathrm{F}_{1 \mathrm{t}}$-PhytoP + ent-16-epi-16- $\mathrm{F}_{1 \mathrm{t}}$-PhytoP (PP2); 9-epi-9- $\mathrm{F}_{1 \mathrm{t}}-\mathrm{Phy}-$ toP (PP3); 9- $\mathrm{D}_{1 \mathrm{t}}$-PhytoP (PP4); 9-epi-9- $\mathrm{D}_{1 \mathrm{t}}$-PhytoP (PP5); ent-16-
$\mathrm{B}_{1}-$ PhytoP + 16- $\mathrm{B}_{1}-$ PhytoP (PP6); ent-9- $\mathrm{L}_{1}-\mathrm{PhytoP}+9-\mathrm{L}_{1}-\mathrm{PhytoP}$ (PP7)) and the PhytoFs (ent-16-(RS)-9-epi-ST- $\Delta^{14}-10-$ PhytoF (PF1); ent-9-(RS)-12-epi-ST- $\Delta^{10}$-13-PhytoF (PF2); ent-16-(RS)-13-epi-ST$\Delta^{14}$-9-PhytoF (PF3)) (cited by elution order) (Table 2) were synthesized according to our previously published procedures ${ }^{11,21-25}$ and provided by the Institut des Biomolécules Max Mousseron (IBMM) (Montpellier, France). Hexane was obtained from Panreac (Castellar del Vallés, Barcelona, Spain), butylated hydroxyanisole (BHA) and bis-Tris (bis(2-hydroxyethyl) amino-tris (hydroxymethyl) methane) were purchased from Sigma-Aldrich (St. Louis, MO, USA), and all LC-MS grade solvents, methanol, and acetonitrile were from J.T. Baker (Phillipsburg, NJ, USA). Water was treated in a milli-Q water purification system from Millipore (Bedford, MA, USA). The SPE cartridges used were Strata cartridge (Strata X-AW, $100 \mathrm{mg} / 3 \mathrm{~mL}$ ), which were acquired from Phenomenex (Torrance, CA, USA).

Sample and Standard Preparation. Samples consisted of grain from 14 rice (Oryza sativa L.) cultivars, which were grown in Mid-East Argentina, in the Experimental Station "Julio Hirschhorn", de La Plata $\left(34^{\circ} 52^{\prime} \mathrm{S}, 57^{\circ} 57^{\prime} \mathrm{W}, 9.8 \mathrm{~m}\right.$ of altitude, Buenos Aires, Argentina). Climatic data were recorded during the growing season (October2015/April-2016) including minimum and maximum temperatures $\left({ }^{\circ} \mathrm{C}\right)$, relative humidity $(\%)$, and monthly rainfall (Table 1$)$. The panel of rice cultivars included eight (8) of indica subspecies ('Cambá, 'Don Ignacio FCAyF', 'Don Justo FCAyF', 'El Paso 144', 'Guri INTA', 'IRGA 424', 'Nutriar FCAyF', and 'Puitá') and six (6) of japonica subspecies ('Amaroo', 'Arborio', 'Itapé, 'Quebracho FA', 'Yamani', and 'Yerua FA'). Seeds were harvested in dry land, manually at a rate of 350 seeds $\mathrm{m}^{-2}$ in lines at $0.20 \mathrm{~m}$, in plots of $5 \mathrm{~m}^{2}$. The trials were conducted with flood irrigation from 30 days of emergence. Harvesting and threshing were done manually; the grains were dried in an oven at $41{ }^{\circ} \mathrm{C}$ for $72 \mathrm{~h}$. Polishing was performed at room temperature from $100 \mathrm{~g}$ of paddy rice. Husk and bran layers were removed using an experimental mill (Guidetti and Artioli Universal Type, Renazzo, Italy). Milling of rice materials was done at low speeds, and during this process temperature was continuously monitored, avoiding increases higher than $1{ }^{\circ} \mathrm{C}$ relatively to the initial conditions of the raw materials. Ground rice flour was obtained in a $0.4 \mathrm{~mm}$ mesh Cyclone Mill. Rice flour samples were stored at $4{ }^{\circ} \mathrm{C}$, protected from light , until analytical assessment.

Stock solutions of PhytoPs and PhytoFs were prepared in methanol/water $(50: 50, \mathrm{v} / \mathrm{v})$ to facilitate the ionization in the mass spectrometer at a concentration of $1000 \mathrm{nM}$ for each compound and stored in Eppendorf tubes at $-80{ }^{\circ} \mathrm{C}$. Five successive $1 / 4$ dilutions were freshly prepared each day of analysis to obtain standard solutions at the following concentrations: $250,63,16,4$, and $2 \mathrm{nM}$, which were used for obtaining the calibration curves.

Extraction of Phytoprostanes and Phytofurans. The PhytoPs and PhytoFs present in rice flours were extracted following the methodology described by Leung et al. (2014) and Yonny et al. (2016) with minor modifications. ${ }^{8,12}$ Briefly, samples (4 g) were crushed in a mortar and pestle with $10 \mathrm{~mL}$ of methanol (0.1\% BHA). The samples extracts were centrifuged at $2000 \mathrm{~g}$ during $10 \mathrm{~min}$, and supernatants were further processed upon solid phase extraction (SPE) using a Chromabond $\mathrm{C}_{18}$ column according to the procedure previously described. ${ }^{26}$ Target compounds were eluted with $1 \mathrm{~mL}$ of methanol and dried using a SpeedVac concentrator (Savant SPD121P, Thermo Scientific, MA, USA). The dry extracts were reconstituted with $200 \mu \mathrm{L}$ of solvent A/solvent B (50:50, v/v), solvent A being MilliQ-water/acetic acid (99.99:0.01, v/v) and solvent B being methanol/ 
acetic acid (99.99:0.01, v/v). Reconstituted samples were filtered through a $0.45-\mu \mathrm{m}$ filter (Millipore, MA, USA) and immediately analyzed by UHPLC-ESI-QqQ-MS/MS (Agilent Technologies, Waldbronn, Germany).

UHPLC-ESI-QqQ-MS/MS Analysis. Chromatographic separation of PhytoPs and PhytoFs was performed using a UHPLC coupled with a 6460 triple quadrupole-MS/MS (Agilent Technologies, Waldbronn, Germany), using the analytical column BEH $\mathrm{C}_{18}(2.1 \mathrm{~mm} \times 50 \mathrm{~mm}$, $1.7 \mu \mathrm{m}$ ) (Waters, Milford, M.A.). The column temperatures were $6{ }^{\circ} \mathrm{C}$ (both left and right). The mobile phases consisted of Milli-Q-water/ acetic acid (99.99:0.01, v/v) (A) and methanol/acetic acid (99.99:0.01, v/v) (B). The injection volume and flow rate were 20 $\mu \mathrm{L}$ and $0.2 \mathrm{~mL} \mathrm{~min}^{-1}$ upon the following linear gradient (time (min), $\% \mathrm{~B}):(0.00,60.0 \%) ;(2.00,62.0 \%) ;(4.00,62.5 \%) ;(8.00,65.0 \%)$; and $(8.01,60.0 \%)$. An additional postrun of $1.5 \mathrm{~min}$ was considered for column equilibration. The spectrometric analysis was conducted in Multiple Reaction Monitoring mode (MRM) operated in negative mode, assigning preferential MRM transition for the corresponding analytes. The ionization and fragmentation conditions were as follows: gas temperature $325{ }^{\circ} \mathrm{C}$, gas flow $8 \mathrm{~L} \mathrm{~min}^{-1}$, nebulizer $30 \mathrm{psi}$, sheath gas temperature $350{ }^{\circ} \mathrm{C}$, jetstream gas flow $12 \mathrm{~L} \mathrm{~min}{ }^{-1}$, capillary voltage $3000 \mathrm{~V}$, and nozzle voltage $1750 \mathrm{~V}$, according to the most abundant product ions. Data acquisition and processing were performed using Mass Hunter software version B.04.00 (Agilent Technologies). The quantification of PhytoPs and PhytoFs detected in rice grain and flour was performed using authentic standards according to standard curves freshly prepared as mentioned in the previous section. The selected reaction monitoring and chemical names were according to the nomenclature system of Taber et al. (1997) and are provided in Table $2 .{ }^{27}$

Table 2. Selected Reaction Monitoring of the Phytoprostanes and Phytofurans Present in Rice (Oryza sativa L.) Flours ${ }^{a}$

\begin{tabular}{|c|c|c|c|c|c|c|}
\hline code & compound & $\begin{array}{c}R_{\mathrm{t}} \\
(\mathrm{min})\end{array}$ & $\begin{array}{l}\text { precursor } \\
\text { ion }(m / z)\end{array}$ & $\begin{array}{l}\text { product } \\
\text { ion } \\
(m / z)\end{array}$ & $F(\mathrm{~V})$ & CE (V) \\
\hline \multicolumn{7}{|c|}{ Phytoprostanes } \\
\hline PP1 & 9- $\mathrm{F}_{1 \mathrm{t}}-\mathrm{PhytoP}$ & 1.943 & 327.2 & 171.2 & 80 & 0 \\
\hline PP2 & 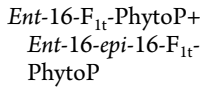 & 2.088 & 327.2 & 251.2 & 80 & 0 \\
\hline PP3 & 9-epi-9- $\mathrm{F}_{1 \mathrm{t}}$-PhytoP & 2.144 & 327.2 & 171.2 & 80 & 0 \\
\hline PP4 & 9-epi-9- $\mathrm{D}_{1 \mathrm{t}}$-PhytoP & 2.151 & 325.2 & 307.2 & 80 & 0 \\
\hline PP5 & 9- $\mathrm{D}_{1 \mathrm{t}}-\mathrm{PhytoP}$ & 2.510 & 325.2 & 307.2 & 80 & 0 \\
\hline PP6 & 16- $\mathrm{B}_{1}-$ PhytoP & 3.224 & 307.2 & 235.2 & 70 & 0 \\
\hline PP7 & 9- $\mathrm{L}_{1}$-PhytoP & 3.481 & 307.2 & 185.2 & 70 & 0 \\
\hline \multicolumn{7}{|c|}{ Phytofurans } \\
\hline PF1 & $\begin{array}{l}\text { Ent-16-(RS)-9-epi- } \\
\text { ST- } \Delta^{14}-10-\text { PhytoF }\end{array}$ & 1.722 & 343.4 & 209.2 & 90 & 20 \\
\hline PF2 & $\begin{array}{l}\text { Ent-9-(RS)-12-epi- } \\
\text { ST- } \Delta^{10}-13 \text {-PhytoF }\end{array}$ & 1.711 & 343.3 & 237.4 & 115 & 25 \\
\hline PF3 & $\begin{array}{c}\text { Ent-16-(RS)-13-epi- } \\
\text { ST- } \Delta^{14}-9 \text {-PhytoF }\end{array}$ & 1.725 & 342.9 & 201.2 & 100 & 30 \\
\hline
\end{tabular}

${ }^{a} R_{\mathrm{v}}$, retention time; $F$, fragmentor; CE, collision energy.

Statistical Analysis. All assays were developed in triplicate $(n=$ 3 ), and values were reported as means. To determine the effect of the type of flour on target compounds, one-way analysis of variance (ANOVA) and multiple range test (Tukey's test) were carried out using Statgraphics Centurion XVI (StatPoint Technologies Inc., Warranton, VA, USA). Significant differences were set at $p<0.05$. A Pearson's correlation analysis was developed to corroborate the relationship between both groups of compounds (PhytoPs and PhytoFs), concerning both individual and total compounds. The significance of the correlations found was set at $p<0.05$.

\section{RESULTS AND DISCUSSION}

For the evaluation of rice flours on the concentration of PhytoPs and PhytoFs, crops were set up in an experimental field of the Buenos Aires province, in Mid-East Argentina, and included 8 indica varieties ('Cambá', 'Don Ignacio FCAyF', 'Don Justo FCAyF', 'El Paso 144', 'Guri INTA', 'IRGA 424', 'Nutriar FCAyF', and 'Puitá') and 6 japonica cultivars ('Amaroo', 'Arborio', 'Itapé, 'Quebracho FA', 'Yamani', and 'Yerua FA'). The crops were developed under the climatic conditions specified in Table 1, which lead to the normal development of the rice crops although, given the role of PhytoPs and PhytoFs in stress response, contributed to define the final levels of the target compounds in the plant material.

Occurrence of Phytoprostanes and Phytofurans in Rice Flours. When we analyzed the content of total PhytoPs and PhytoFs in rice flour obtained from grains of 14 rice cultivars by monitoring the relationship of the cultivar and the type of flour, we found that total PhytoP concentration was significantly higher in white and brown flours obtained from japonica varieties (12.23 and $16.14 \mathrm{ng} \mathrm{g}^{-1} \mathrm{dw}$, respectively) than in those of indica (a 36.7\% and 6.1\% lower, respectively). This trend was reversed when considering rice bran, in which content of PhytoPs was $2.4 \%$ higher, on average, in plant material from indica subspecies than in those corresponding to japonica (Table 3).

The comparison of individual varieties concerning their content in total PhytoPs, revealed that, regarding white grain flour, the indica cultivar 'Guri INTA' and the japonica varieties 'Arborio' and 'Quebracho FA' presented the highest concentrations at average values around $22.02 \mathrm{ng} \mathrm{g}^{-1} \mathrm{dw}$ (Table 3). In a second group, the cultivars 'Camba' (indica), 'Itapé' (japonica), and 'Yamami' (japonica) were stressed with values ranging from 9.14 to $9.98 \mathrm{ng} \mathrm{g}^{-1} \mathrm{dw}(66.0 \%$ lower than the former ones, on average). Finally, the lowest concentration of total PhytoPs corresponded to the varieties 'IRGA 424' (indica) = 'Puritá' (indica) = 'Yerua FA' (japonica) (6.76 ng g ${ }^{-1} \mathrm{dw}$, on average $)>$ 'Nutriar FCAyF' (indica) $=$ 'El paso 144' (indica) $=$ 'Amaroo' (japonica) (4.78 $\mathrm{ng} \mathrm{g}^{-1} \mathrm{dw}$, on average) > 'Don Justo FCAyF' (indica) = 'Don Ignacio FCAyF' (indica), $\left(2.80 \mathrm{ng} \mathrm{g}^{-1}\right.$ $\mathrm{dw}$, on average) (Table 3).

With respect to brown grain flours, the relative abundance of total PhytoPs in indica and japonica varieties evidenced that the concentration decreases as follows: 'Itapé' (japonica) (32.89 ng $\mathrm{g}^{-1} \mathrm{dw}$ ) > 'Quebracho FA' (japonica) = 'Don Justo FCAyF' (indica) $=$ 'Camba' (indica) $=$ 'Yamani' (japonica $)=$ 'Nutriar FCAyF' (indica) = 'Don Ignacio FCAyF' (indica) $\left(22.03 \mathrm{ng} \mathrm{g}^{-1}\right.$ $\mathrm{dw}$, on average $)>$ 'Puitá' (indica) $=$ 'El Paso 144' (indica) $=$ 'Guri INTA' (indica) = 'Amaroo' (japonica) = 'Yerua FA' (japonica) > 'IRGA 424' (indica) = 'Arborio' (japonica) (13.39 ng $\mathrm{g}^{-1} \mathrm{dw}$, on average) (Table 3 ).

Apart from the flour obtained from white and brown rice grains, rice bran, which is constituted by the hard outer layers of grain, consisting of the combined aleurone and pericarp, exhibited a reverse trend for total PhytoPs. In this case, the highest concentration corresponded to the indica varieties 'El Paso 144' (118.00 $\mathrm{ng} \mathrm{g}^{-1} \mathrm{dw}$ ) and 'Guri INTA' (106.67 $\mathrm{ng} \mathrm{g}^{-1}$ $\mathrm{dw}$ ), which surpassed the levels observed in 'IRGA 424', 'Puitá', 'Don Ignacio FCAyF', 'Nutriar FCAyF', 'Itapé, 'Arborio', and 'Amaroo' by $34.0 \%$, on average. The lowest concentration corresponded to the cultivars 'Quebracho FA', 'Arborio', 'Don Justo FCAyF', 'Yerua FA', and 'Camba' (22.20-54.91 ng g ${ }^{-1} \mathrm{dw}$, on average) (Table 3 ). 
Table 3. Content of Total Phytoprostanes and Phytofurans ${ }^{a}$ in Three Types of Rice (Oriza sativa L.) Grain Flour Cultivars Evaluated Belonging to indica and japonica Subspecies ${ }^{b}$

\begin{tabular}{|c|c|c|c|c|c|c|c|c|}
\hline \multirow[b]{2}{*}{ cultivar } & \multicolumn{4}{|c|}{ total PhytoPs } & \multicolumn{4}{|c|}{ total PhytoFs } \\
\hline & white grain flour & brown grain flour & rice bran & LSD & white grain flour & brown grain flour & rice bran & LSD \\
\hline \multicolumn{9}{|c|}{ Oryza sativa L. subspecies indica } \\
\hline 'Camba' & $9.98 \mathrm{~b} \mathrm{~B}$ & $22.03 \mathrm{bc} \mathrm{A}$ & 22.20 e $\mathrm{A}$ & 1.18 & 0.89 с B & $5.71 \mathrm{bc} \mathrm{A}$ & 3.05 e B & 0.57 \\
\hline 'Don Ignacio FCAyF' & $2.55 \mathrm{f} \mathrm{B}$ & $20.38 \mathrm{bcd} \mathrm{AB}$ & 74.75 bc A & 1.86 & 0.27 ef $\mathrm{B}$ & $5.41 \mathrm{bcd} \mathrm{AB}$ & 8.97 cde A & 0.24 \\
\hline 'Don Justo FCAyF' & $3.04 \mathrm{f} \mathrm{B}$ & $22.53 \mathrm{~b} \mathrm{AB}$ & 39.58 cde A & 7.74 & 0.36 e $\mathrm{B}$ & 4.35 bcde A & 1.59 e $B$ & 0.30 \\
\hline 'El Paso 144’ & 4.83 ef $B$ & 16.39 de $\mathrm{AB}$ & 118.00 a A & 1.31 & $0.77 \mathrm{~cd} \mathrm{C}$ & 3.09 def B & 27.74 a A & 0.45 \\
\hline ‘Guri INTA’ & 22.47 a B & 14.24 ef $B$ & $106.67 \mathrm{ab} A$ & 1.42 & $1.60 \mathrm{ab} \mathrm{B}$ & 1.96 efg B & $22.51 \mathrm{ab} \mathrm{A}$ & 0.60 \\
\hline 'IRGA 424’ & $7.35 \mathrm{~cd} \mathrm{~B}$ & $10.14 \mathrm{f} \mathrm{B}$ & $81.27 \mathrm{abc} \mathrm{A}$ & 0.81 & 0.40 e B & $1.41 \mathrm{fg} \mathrm{B}$ & $15.39 \mathrm{bc} \mathrm{A}$ & 0.53 \\
\hline 'Nutriar FCAyF' & 4.94 ef $B$ & 20.75 bcd B & $68.88 \mathrm{bcd} A$ & 0.01 & 0.41 e $\mathrm{C}$ & 19.49 a A & 7.98 cde B & 2.36 \\
\hline ‘Puitá’ & $6.78 \mathrm{~cd} \mathrm{~B}$ & 17.46 cde B & $76.16 \mathrm{abc} A$ & 0.66 & 0.31 ef $B$ & 2.82 ef $B$ & $14.65 \mathrm{bcd} \mathrm{A}$ & 2.93 \\
\hline \multicolumn{9}{|c|}{ Oryza sativa L. subspecies japónica } \\
\hline 'Amaroo' & 4.58 ef $\mathrm{B}$ & 13.32 ef $\mathrm{B}$ & 60.22 cde A & 5.86 & 0.41 e $A$ & $1.36 \mathrm{fg} \mathrm{A}$ & 7.47 cde A & 2.03 \\
\hline 'Arborio' & 21.86 a B & $9.51 \mathrm{f} \mathrm{C}$ & $65.65 \mathrm{bcd} A$ & 0.91 & 1.79 a B & $0.00 \mathrm{~g} \mathrm{C}$ & 8.66 cde A & 0.21 \\
\hline ‘Itapé’ & $9.14 \mathrm{bC}$ & 32.89 a B & $67.09 \mathrm{bcd} \mathrm{A}$ & 1.24 & $1.45 \mathrm{~b} \mathrm{C}$ & $6.72 \mathrm{~b} \mathrm{~B}$ & $15.08 \mathrm{bc} \mathrm{A}$ & 0.48 \\
\hline 'Quebracho FA' & 21.74 a B & $24.83 \mathrm{~b} \mathrm{~B}$ & 54.91 cde A & 5.69 & 0.06 e $B$ & 3.91 cde $\mathrm{AB}$ & 6.16 cde A & 1.24 \\
\hline 'Yamani' & 9.96 b B & $21.65 \mathrm{bc} \mathrm{AB}$ & 54.32 cde A & 8.41 & 0.48 de B & 4.00 cde $\mathrm{A}$ & 6.02 cde A & 0.81 \\
\hline 'Yerua FA' & 6.15 de $B$ & 12.65 ef $\mathrm{AB}$ & 31.04 de A & 0.52 & 0.35 ef $\mathrm{B}$ & $1.49 \mathrm{fg} \mathrm{B}$ & 3.79 de $\mathrm{A}$ & 0.34 \\
\hline LSD & 2.45 & 4.81 & 41.84 & & 0.29 & 2.41 & 11.02 & \\
\hline \multicolumn{9}{|l|}{ Significance } \\
\hline subspecies indica & $7.79 \mathrm{~B}$ & $17.99 \mathrm{~B}$ & $73.44 \mathrm{~A}$ & 3.90 & $0.63 \mathrm{C}$ & $5.53 \mathrm{~B}$ & $12.74 \mathrm{~A}$ & 1.29 \\
\hline subspecies japonica & $12.30 \mathrm{~B}$ & $19.14 \mathrm{~B}$ & $55.54 \mathrm{~A}$ & 2.79 & $2.91 \mathrm{~B}$ & $2.91 \mathrm{~B}$ & $7.86 \mathrm{~A}$ & 0.70 \\
\hline LSD & 1.35 & 1.31 & 5.49 & & 0.11 & 0.93 & 1.57 & \\
\hline$p$-value ${ }^{c}$ & $* * *$ & ns & $* * *$ & & ns & ns & $* * *$ & \\
\hline
\end{tabular}

${ }^{a}$ Units of ng g ${ }^{-1} \mathrm{dw} .{ }^{b}$ Means $(n=3)$ within a column followed by distinct lowercase letters (cultivar) or within a row (type of flour) followed by distinct uppercase letters are significantly different at $p<0.001$ according to Tukey's multiple range test. ${ }^{c}$ In the bottom of the table means of indica and japonica subspecies were compared resorting to paired $t$ test; significant differences were stated at $p<0.001$ (***) and not significant (ns).

To the best of our knowledge, there is no previous description of the content of PhytoPs in rice flours before this study; however, some works have characterized other vegetable matrices, concerning the concentrations of these compounds, showing 15.00-39.00 ng mL ${ }^{-1}(12.00-31.00 \mathrm{ng}$ $\mathrm{g}^{-1}$ approx), ${ }^{11} 0.01-0.06 \mathrm{ng} \mathrm{g}^{-1} \mathrm{dw}$ in algae, ${ }^{28} 5.81-9.99 \mathrm{ng}$ $\mathrm{g}^{-1}$ in raw green table olive fruits, ${ }^{29}$ and $40.25-238.09 \mathrm{ng} \mathrm{g}^{-1}$ in almonds. ${ }^{7}$ To date, the highest concentration of total PhytoPs was observed in fresh birch pollen with values of up to 1380.00 $\mathrm{ng} \mathrm{\textrm {g } ^ { - 1 } , 4}$ and in dry leaves of melon plants with a maximum values of $1600 \mathrm{ng} \mathrm{g}^{-1} \mathrm{dw}^{8}$ Their level in almonds and sunflower oil is similar possibly because of its high lipid content with an average of $56.0 \%$ of the dry matter. ${ }^{30}$ Hence, when comparing the data retrieved from the present work with those in the literature, it is noticed that there is a higher amount of PhytoPs in rice flour than in algae, green olives, and olive oil, but less than that in almonds and melon leaves.

In addition to PhytoPs, recently another series of plant oxylipins, PhytoFs, has been described. These compounds are oxylipins sharing chemical structure analogies with PhytoPs generated favorably over PhytoPs by nonenzymatic oxidative reactions, but under higher oxygen pressure than PhytoPs. ${ }^{25}$ The assessment of rice flours for PhytoFs revealed that the preponderance in indica and japonica subspecies of these compounds is closely dependent on the type of flour (Table 3). The japonica cultivars presented the highest concentration of total PhytoFs concerning white grain flour (2.91 $\mathrm{ng} \mathrm{g}^{-1} \mathrm{dw}$ ), while indica subspecies were determined as the ones with the highest contents of PhytoFs in brown grain and rice bran (5.53 and $12.74 \mathrm{ng} \mathrm{g}^{-1} \mathrm{dw}$, respectively). In addition, the concentration of PhytoFs seems to be lower than the level of PhytoPs, which has been attributed to the specific phys- icochemical features of the panel of foods and foodstuffs evaluated, which include very low water content, ${ }^{31}$ and lower oxidation conditions than required for the synthesis of PhytoFs. ${ }^{25}$

In addition to differences concerning the content of total PhytoFs between indica and japonica subspecies of rice, the evaluation of individual cultivars evidenced that higher concentrations of PhytoFs in rice grain flours are close dependent on the type of rice-derived plant material considered (white or brown grains or rice bran). In this sense, regarding white grain flour, the highest concentrations corresponded to the indica cultivar 'Guri INTA', as well as the japonica varieties 'Arborio' and 'Itapé' (1.61 $\mathrm{ng} \mathrm{g}^{-1} \mathrm{dw}$, on average), followed by 'Camba' and 'El Paso 144' (both belonging to the indica subspecies) (0.83 $\left.\mathrm{ng} \mathrm{g}^{-1} \mathrm{dw}\right)$. Contrarily, the remaining cultivars featured similarly lower values ranging from 0.06 to $0.48 \mathrm{ng} \mathrm{g}^{-1} \mathrm{dw}$ (Table 3).

When considering brown grain flour, the highest concentration of total PhytoFs was found in the cultivar 'Nutriar FCAyF', which displayed values of $19.49 \mathrm{ng} \mathrm{g}^{-1} \mathrm{dw}$, surpassing the samples of flour obtained from the indica cultivars 'Camba', 'Don Ignacio FCAyF', 'Don Justo FCAyF', and 'El Paso 144' and the japonica varieties 'Itapé, 'Quebracho FA', and 'Yamani' by $75.7 \%$, on average. The lowest concentration of total PhytoFs corresponded to the cultivars 'Guri INTA', 'IRGA 424', 'Puitá', 'Amaroo', 'Arborio', and 'Yerua FA' (1.11 ng g $\mathrm{dw}$, on average) (Table 3).

Finally, with respect to the concentration of PhytoFs in rice bran, the highest values were observed in the indica varieties 'El Paso 144' and 'Guri INTA'(25.13 $\mathrm{ng} \mathrm{g}^{-1} \mathrm{dw}$, on average), followed by the indica cultivars 'IRGA 424' and 'Puitá', as well 

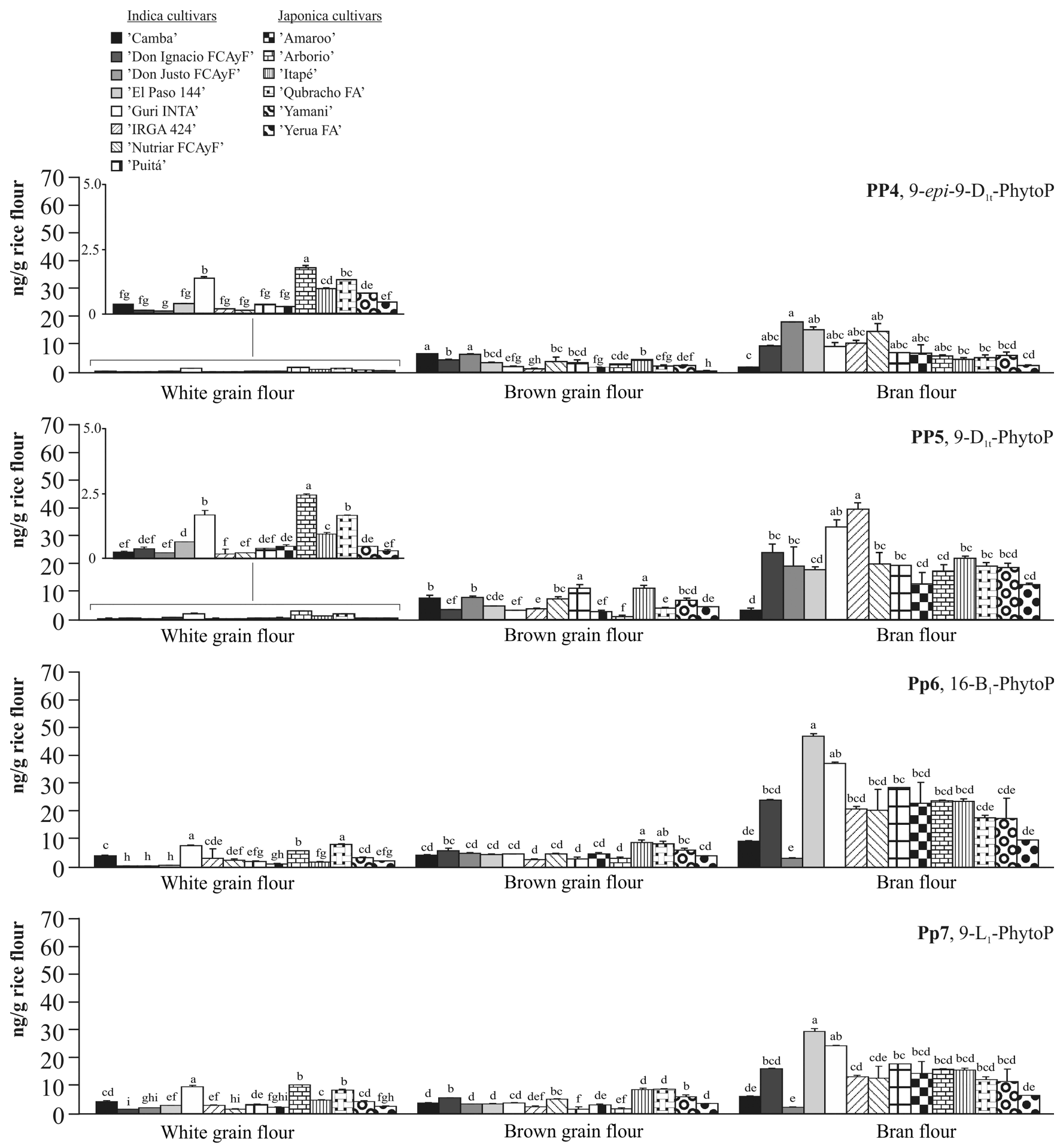

Type of rice flour

Figure 1. Comparison between rice subspecies and types of flour regarding individual phytoprostanes, 9-D1t-PhytoP (PP4), 9-epi-9-D1t-PhytoP (PP5), 16-B1-PhytoP (PP6), and 9-L1-PhytoP (PP7). Different lowercase letters indicate significant differences between varieties for the same flour type at $p<0.05$, according to the analysis of variance (ANOVA) and the multiple range test of Tukey.

as the japonica cultivar 'Itapé', which presented concentrations a $40.2 \%$ lower than the former, on average (Table 3).

To date, there is limited information on the occurrence of PhytoFs in plant materials and foods, concerning both profile and quantitative levels, ${ }^{25}$ which makes it difficult to understand the actual scope of these compounds regarding their physiological role in plants, as well as to design experimental procedures addressed to retrieve mechanistic information on the biological interest of such bioactive molecules once ingested. Nonetheless, the comparison of results on the concentration of total PhytoFs in rice flours (0.06-27.74 ng $\mathrm{g}^{-1} \mathrm{dw}$ ) with data available in the literature allows us to notice concentrations consistent with the levels reported in pine, walnuts, chia, and flax $\left(0.30,9.00,6.00\right.$, and $0.70 \mathrm{ng} \mathrm{g}^{-1}$, on average, respectively), ${ }^{32}$ remaining in much lower concen- 


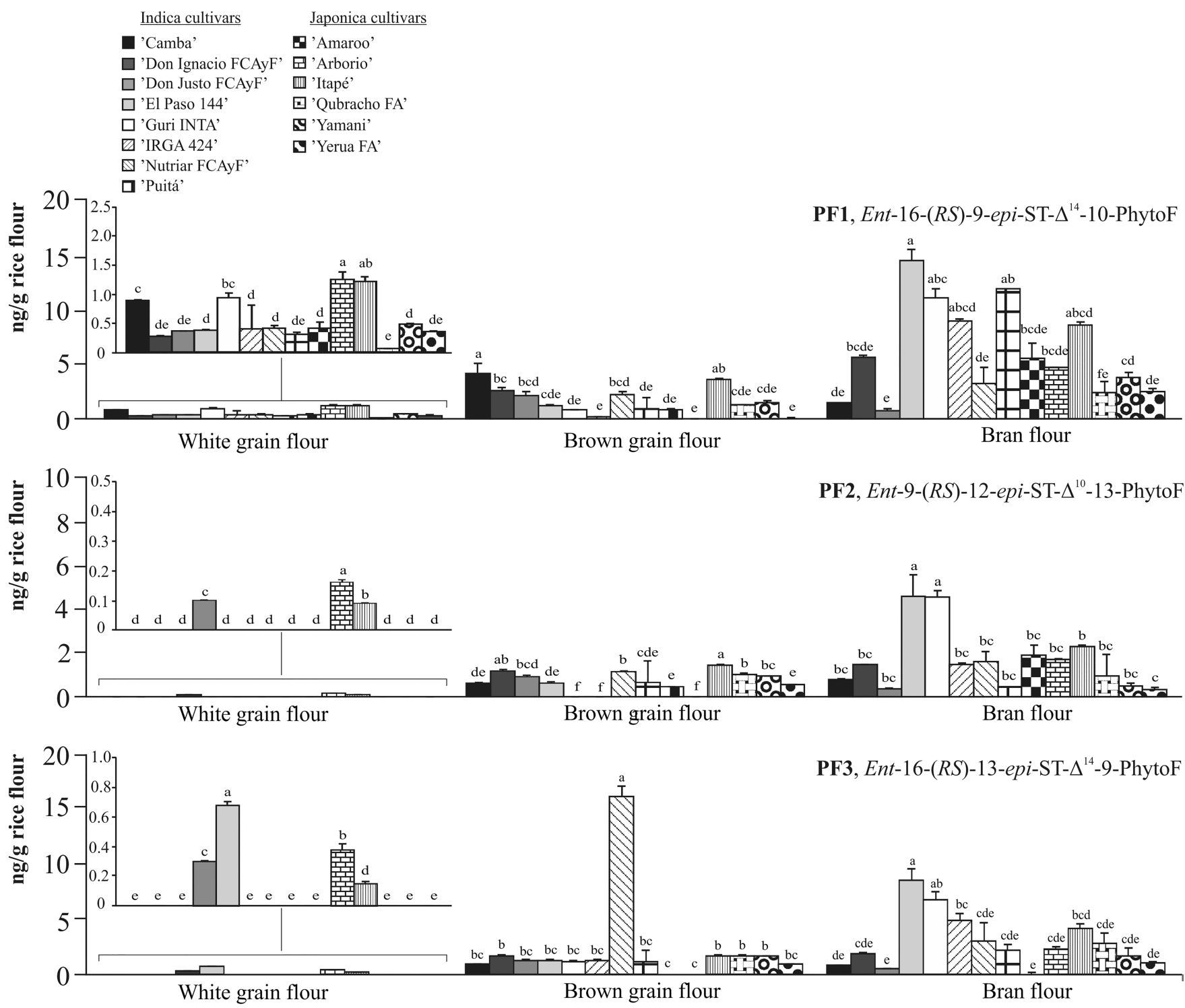

Type of rice flour

Figure 2. Comparison between rice subspecies and types of flour regarding individual phytofurans, ent-16-(RS)-9-epi-ST- $\Delta 14-10-\mathrm{PhytoF}$ (PF1), ent-9-(RS)-12-epi-ST- $\Delta$ 10-13-PhytoF (PF2), and ent-16-(RS)-13-epi-ST- $\Delta$ 14-9-PhytoF (PF3). Different lowercase letters indicate significant differences between varieties for the same flour type at $p<0.05$, according to the analysis of variance (ANOVA) and the multiple range test of Tukey.

trations than, for instance, that in melon leaves $(130-4400 \mathrm{ng}$ $\left.\mathrm{g}^{-1}\right) .^{8}$

The higher concentration of PhytoPs and PhytoFs in whole grain and rice bran in comparison with white and brown rice flours in addition to indicating the most adequate dietary source of these compounds (concerning rice) has a side consequence. In addition to being better sources of PhyoPs and PhytoFs, whole grain and rice bran can exert beneficial effects upon the gastrointestinal tract given their contribution to the proportion of dietary fiber. In fact, this specific composition (dietary fiber) could be related with the proper intestinal absorption of PhytoPs and PhytoFs. ${ }^{33}$ Although the fiber content is low in rice bran, it has high oil content with an unusually high concentration of unsaponifiable healthy fatty acids that also are responsible for hypolipidemic effects $(4.2 \%){ }^{34}$ Hence, soluble fiber acquires gel-like consistency and helps to control glycemia and excessive plasma cholesterol, which entails multiple metabolic consequences.
Influence of Rice Flour Type on the Content of Total Phytoprostanes and Phytofurans. As a general trend, when comparing the concentration of PhytoPs and PhytoFs in rice flours of diverse origins at different processing levels, it was noticed that the highest concentration corresponded to bran (22.20-106.67 and 1.59-27.74 $\mathrm{ng} \mathrm{g}^{-1} \mathrm{dw}$ of PhytoPs and PhytoFs, respectively), followed by brown grain flour (10.1422.53 and 9.51-24.83 $\mathrm{ng} \mathrm{g}^{-1} \mathrm{dw}$ of PhytoPs and PhytoFs, respectively), while white grain flour presented the lowest levels (2.55-22.47 and 0.06-1.79 $\mathrm{ng} \mathrm{g}^{-1} \mathrm{dw}$ of PhytoPs and PhytoFs, respectively) (Table 3 ). The decreasing concentration of the target molecules recorded upon the present work (bran > brown grain flour $>$ white grain flour) is in agreement with their content in polyunsaturated fatty acids (PUFAs) in general and specifically regarding ALA, according to previous descriptions available in the literature that describe the preponderant concentration of lipids in rice bran $(22.5 \%)$, relatively to whole rice $(2.3 \%)$ and polished rice $(0.8 \%) .^{20}$ 
It is important to stress that lipids in the endosperm are present in different forms relatively to bran and germ. In addition, based on the association with starch (stabilized with van der Waals contacts), rice lipids are often classified as starch and nonstarch lipids. ${ }^{35}$ Hence, nonstarch lipids are found mainly in the lipid bodies of rice bran (aleurone layer) and germ (embryo), while starch lipids are associated with starch granules in the rice endosperm. This indicates that rice phospholipids may have significant impacts on traditional (storage, cooking, and food) and modern (glycemic index) concepts related to rice quality. Besides, although this fact has been broadly reported in the literature, much of the information available on the occurrence and distribution of phospholipids in rice, their effects on storage and food quality, and the implications for human health is scattered with little consensus. ${ }^{36}$ Hence, given the close relationship between the occurrence of PUFAs and PhytoPs/PhytoFs, in the next years research efforts should be focused on retrieving the exact connection between the phospholipid distribution and the level of PhytoPs and PhytoFs, as well as their contribution to rice quality and eventually human health to the extent which new data on bioavailability and pharmacokinetics become available.

Influence of Rice Flour Type on the Content of Individual Phytoprostanes and Phytofurans. From a thoughtful analysis of the results obtained, it is noticed that the relative occurrence of individual PhytoPs was dependent on the specific compounds evaluated, although as a general trend the highest concentration was observed in rice bran, followed by brown grain flour and white grain flour (Figures 1 and 2). This fact seems to be due to the higher exposition of bran (constituted by pericarp, seed coat, micelles, and aleurone layer) to external aggressions, which enhance reactive oxygen species (ROS) production in the different compartments and thus result in an increased formation of an array of lipid peroxidation products including PhytoPs and PhytoFs. ${ }^{11,37}$

In addition, significant differences have been found between cultivars belonging to both indica and japonica subspecies. The comparison of these two subspecies evidenced that individual PhytoPs in white grain flour were significantly higher in materials from japonica relatively to those belonging to indica subspecies ( $44.8 \%$ lower, on average), while in rice bran the trend was the opposite $(23.3 \%$ lower in japonica cultivars than in the indica ones, on average). With respect to brown grain flour, no differences were observed between both subspecies (Figures 1). When evaluating the distinct values of indica and japonica cultivars concerning their concentration of individual PhytoFs, concentrations $38.2 \%$ higher were observed in bran of indica subspecies than in that of japonica origin (Figures 2).

Among the individual PhytoPs and PhytoFs identified in the plant material evaluated in the present work (7 and 3, respectively), the presence of the PhytoPs 9-epi-9- $\mathrm{D}_{1 \mathrm{t}}-\mathrm{Phyto}$, 9- $\mathrm{D}_{1 \mathrm{t}}$-PhytoP, 16- $\mathrm{B}_{1}-$ PhytoP, and 9- $\mathrm{L}_{1}-\mathrm{PhytoP}$ and the PhytoFs ent-16-(RS)-9-epi-ST- $\Delta^{14}-10-\mathrm{PhytoF}$, ent-9-(RS)-12epi-ST- $\Delta^{10}-13$-PhytoF, and ent-16-(RS)-13-epi-ST- $\Delta^{14}-9$-PhytoF (Table 2, and Figures 1 and 2) were observed. When evaluating the concentration of such individual compounds, regarding PhytoPs, we found that $16-\mathrm{B}_{1}-$ PhytoP $(52.79 \mathrm{ng} / \mathrm{g}$ $\mathrm{dw}$, on average, in rice bran of the indica subspecies, var. 'El Paso 144' and 'Guri INTA'), 9-D $1 \mathrm{t}$-PhytoP (28.98 ng/g dw, on average, in rice bran of the indica subspecies, var. 'Guri INTA' and 'IRGA 424'), and 9- $\mathrm{L}_{1}$-PhytoP (27.04 ng/g, on average, in rice bran of the indica subspecies, var. 'El Paso 144' and 'Guri INTA') were most abundant. The comparison of these concentrations with those in white and brown grain flours did not inform on significant differences between varieties, while all of them displayed values much lower than those in rice bran (Figure 1). Given the lack of previous descriptions of the concentration of PhytoPs in rice and its derivatives, the development of a proper rational discussion should be done on additional food and foodstuff matrices. So, these results are in agreement (in terms of concentration ranges) with the values reported previously in extra virgin oil, olive oil, and refined sunflower oil. ${ }^{23}$ However, regarding the relative contribution of each individual compound, the profile of PhytoPs was different relative to vegetable oils and other plant matrices such almonds, melon leaves, algae, must, and wines, which featured the predominance of $\mathrm{F}_{1}-$ PhytoPs. $^{5-8,28}$ The gap of proper matching on the PhytoP profile of rice flours with previous descriptions available in the literature might be due to the specific physical features of the diverse plant matrices under comparison (moisture and fatty acid profile) but also by the differential processing procedures that may condition the transformation of PUFAs into this and other PhytoPs upon nonenzymatic oxidation reactions. ${ }^{2}$ Given these differences, the rational attribution to these foods and foodstuffs of biological benefits based on the content of PhytoPs needs to be further demonstrated by studies devoted to the assessment of the molecular pathways affected in which these compounds could be involved.

Besides PhytoPs, upon nonenzymatic reactions, PUFAs can give rise to PhytoFs as a consequence of additional oxygenation after the initial endoperoxide formation. These compounds, assessment of which in plant material is in its infancy, ${ }^{11}$ were almost absent in white grain flour, especially concerning ent-9(RS)-12-epi-ST- $\Delta^{10}$-13-PhytoF and ent-16-(RS)-13-epi-ST- $\Delta^{14}$ 9-PhytoF, while ent-16-(RS)-9-epi-ST- $\Delta^{14}-10-$ PhytoF was found in values ranging from 0.06 to $1.25 \mathrm{ng} \mathrm{g}^{-1} \mathrm{dw}$. The highest concentration of ent-16-(RS)-9-epi-ST- $\Delta^{14}-10-\mathrm{PhytoF}$ in white rice flour corresponded to the japonica subspecies var. 'Arborio' and 'Itapé' that exhibited $1.23 \mathrm{ng} \mathrm{g}^{-1} \mathrm{dw}$, on average (Figure 2). The evaluation of the concentration of PhytoFs in brown rice flour informed on no large differences with values within the range $0.00-4.21,0.00-1.45$, and $0.00-16.06 \mathrm{ng} \mathrm{g}^{-1}$ $\mathrm{dw}$ for ent-16-(RS)-9-epi-ST- $\Delta^{14}-10-\mathrm{PhytoF}$, ent-9-(RS)-12-epiST- $\Delta^{10}-13-P h y t o F$, and ent-16-(RS)-13-epi-ST- $\Delta^{14}-9-P h y t o F$, respectively (Figure 2), without a consistent trend on the preponderance of any of the indica and japonica cultivars under study. Finally, regarding the occurrence of PhytoFs in rice bran, as above-mentioned, a preponderance in the indica varieties in comparison with the japonica ones (38.2\% lower on average for the three PhytoFs identified) was observed. In addition, in this flour type the highest concentrations of ent-16-(RS)-9-epi-ST$\Delta^{14}$-10-PhytoF, ent-9-(RS)-12-epi-ST- $\Delta^{10}-13$-PhytoF, and ent16-(RS)-13-epi-ST- $\Delta^{14}$-9-PhytoF corresponded consistently to the varieties 'Quabracho FA', and 'Yamani', which featured average concentrations of $12.88,4.62$, and $7.63 \mathrm{ng} \mathrm{g}^{-1} \mathrm{dw}$, respectively (Figure 2), surpassing the amounts present in the remaining varieties by $61.3 \%, 74.9 \%$, and $73.0 \%$, on average, respectively. In this case, given that all varieties were processed by equal procedures, the differences observed seem to be a consequence of the biochemical composition of such materials.

The comparison of the features of rice brans concerning the occurrence of PhytoFs is hindered by the gap existing in the literature on these compounds. Actually, to date, 16-(RS)-9-epiST- $\Delta^{14}$-10-PhytoF has been described in pine nut, walnut, chia seed, and flax seed nuts, which has shown concentrations of 
Table 4. Analysis of Correlation between the Individual Phytoprostanes and Phytofurans Present in Rice (Oryza sativa L.) Flours $^{a}$

\begin{tabular}{|c|c|c|c|c|c|c|}
\hline & PP5 & PP6 & PP7 & PF1 & PF2 & PF3 \\
\hline PP4 & $0.750 * * *$ & $0.395^{*}$ & $-0.027^{\text {ns. }}$ & $0.537^{* *}$ & $0.547^{* * *}$ & $0.349^{*}$ \\
\hline PP5 & & $0.415^{* *}$ & $0.026^{\mathrm{ns}}$ & $0.711 * * *$ & $0.654 * * *$ & $0.454^{* *}$ \\
\hline PP6 & & & $0.462 * *$ & $0.526^{* *}$ & $0.681^{* * * *}$ & $0.396^{*}$ \\
\hline PP7 & & & & $0.220^{*}$ & $0.253^{*}$ & $0.181^{*}$ \\
\hline PF1 & & & & & $0.783 * * *$ & $0.510^{* * *}$ \\
\hline PF2 & & & & & & $0.591^{* *}$ \\
\hline
\end{tabular}

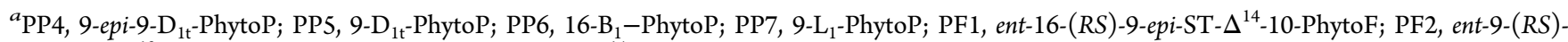
12-epi-ST- $\Delta^{10}$-13-PhytoF; PF3, ent-16-(RS)-13-epi-ST- $\Delta^{14}$-9-PhytoF; ns, not significant and $* * *$, significant at $p<0.001$.

$0.30,9.00,6.00$, and $0.70 \mathrm{ng} \mathrm{\textrm {g } ^ { - 1 }}$, respectively. Besides, the concentration of ent-9-(RS)-12-epi-ST- $\Delta^{10}-13$-PhytoF in walnuts and chia seeds was reported in levels up to 20-fold higher than in flaxseeds and pine. ${ }^{11}$ Both PhytoFs have been also detected in melon leaves at much higher concentrations with values ranging from 130 to $4400 \mathrm{ng} \mathrm{g}^{-1,8}$, although the role of leaves as vegetative plant material could be responsible for such differences, requiring further analysis to set the link between plant physiology and the occurrence of PhytoPs and PhytoFs. In this sense, it is required to state that PhytoPs are components of an archaic signaling system that detects lesions by oxidants and might contribute to protect plants from stress. In this connection, the different concentrations reported could be related to an adaptive response that would provide the plant with a survival advantage through detoxification and stress responses. $^{17}$

Correlation between Phytoprostanes and Phytofurans. The analysis of correlation between the concentration of total and individual PhytoPs and PhytoFs, allowed us to find that the total concentration of both types of compounds are positively and significantly correlated $\left(R^{2}=0.8381, p<0.001\right)$. This correlation could be fueled by the fact that PhytoPs and PhytoFs share, to some extent, biosynthetic pathways, which give rise to one or the other type of oxidative metabolite upon nonenzymatic oxidation at different oxygen tension. ${ }^{11,38}$

In addition, a significant correlation has been observed between individual PhytoPs. In this sense, PhytoP 9-epi-9- $\mathrm{D}_{1 \mathrm{t}^{-}}$ PhytoP is correlated with 9- $\mathrm{D}_{1 \mathrm{t}}$-PhytoP $\left(R^{2}=0.750, p<0.001\right)$ and 16- $\mathrm{B}_{1}$-PhytoP $\left(R^{2}=0.395, p<0.05\right), 9-\mathrm{D}_{1 \mathrm{t}}$-PhytoP with $16-\mathrm{B}_{1}$-PhytoP $\left(R^{2}=0.415, p<0.01\right)$, and $16-\mathrm{B}_{1}$-PhytoP with 9$\mathrm{L}_{1}$-PhytoP $\left(R^{2}=0.462, p<0.01\right)$. Likewise, PhytoFs provided a positive and significant correlation with each other (Table 4). This can be attributed to their common origin as they result from the autoxidation of PUFAs, producing a linolenate radical that readily oxidizes and cyclizes to complex isomeric mixtures without enzymatic intervention and their ability to transform into one another and PhytoPs. ${ }^{2,26}$

In summary, to the best of our knowledge, this is the first work describing the presence of PhytoPs and PhytoFs in rice flours obtained from diverse indica and japonica cultivars, a crop as massive and important for human food ensuring then, a regular and abundant intake of these compounds in worldwide diets. The PhytoPs 9- $\mathrm{D}_{1 \mathrm{t}}-\mathrm{PhytoP}, 16-\mathrm{B}_{1}-\mathrm{PhytoP}$, and 9- $\mathrm{L}_{1}$ PhytoP and the PhytoF ent-16-(RS)-9-epi-ST- $\Delta^{14}-10-$ PhytoF appear as those contributing mostly to the total content of PhytoPs and PhytoFs in the studied food matrices, on which the study of the technological (safety and quality) and biological interest is in its infancy. The highest mean concentrations correspond to rice bran and the lowest to white grain flour. In addition, the occurrence of PhytoFs exhibits average values of $1.77,4.22$, and $10.30 \mathrm{ng} \mathrm{g}^{-1} \mathrm{dw}$ in rice bran, brown grain flour, and white grain flour, respectively. In this concern, the information obtained upon the detailed characterization performed in the present work will allow evaluation of the toxicological and biological activity of PhytoPs and PhytoFs and clarification of the extent to which these compounds could exert valuable biological activities upon in vitro (mechanistic) and in vivo (pharmacokinetic and bioavailability features) study, allocating the effort-focus on the chemical species of these compounds present in cereals. In this connection, in the near future, the rice flour compounds now identified and quantified will be candidate to be further evaluated through proper in vivo trials with experimental animals and humans that would contribute to elucidating how PhytoPs and PhytoFs impact health markers and prevent undesirable pathophysiological situations, cooperating with additional bioactive compounds already evaluated in food and foodstuff matrices.

\section{AUTHOR INFORMATION}

\section{Corresponding Authors}

*A. Gil-Izquierdo. E-mail: angelgil@cebas.csic.com. Tel.: +34968396200, ext. 6363.

*R. Domínguez-Perles. E-mail: rdperles@cebas.csic.com. Tel.: +34968396200, ext. 6253 .

ORCID

R. Domínguez-Perles: 0000-0001-6232-712X

\section{Funding}

This work was partially funded by the "Fundación Séneca de la Región de Murcia" Grupo de Excelencia 19900/GERM/15. This work is included in the framework of the collaboration between the Spanish Research Council (CEBAS-CSIC) and CNRS by "Projets Internationaux de Cooperation Scientifique (PICS-2015-261141). M.P. and R.D.P. were sponsored by a Predoctoral fellowship of the Asociacion Universitaria Iberoamericana de Postgrado (RR 631-2016) of the University of Murcia (Spain) and a Postdoctoral Contract (Juan de la Cierva de Reincorporación ICJI-2015-25373) from the Ministry of Economy, Industry and Competitiveness of Spain, respectively. We thank the English expert reviewer (Dr. David James Walker) for the revision of the English style and grammar.

\section{Notes}

The authors declare no competing financial interest.

\section{ABBREVIATIONS:}

ALA, $\alpha$-linolenic acid; BHA, butylated hydroxy anisole; PhytoPs, phytoprostanes; PhytoFs, phytofurans; PLs, phospholipids; ROS, reactive oxygen species; SPE, solid phase extraction; UHPLC-ESI-QqQ-MS/MS, ultrahigh performance 
liquid chromatography coupled to electrospray ionization and triple quadrupole mass spectrometry

\section{REFERENCES}

(1) Mueller, M. J. Archetype signals in plants: the phytoprostanes. Curr. Opin. Plant Biol. 2004, 7, 441-448.

(2) Collado-González, J.; Durand, T.; Ferreres, F.; Medina, S.; Torrecillas, A.; Gil-Izquierdo, A. Phytoprostanes. Lipid Technol. 2015, 27 (6), 127-130.

(3) Carrasco-Del Amor, A. M.; Aguayo, E.; Collado-González, J.; Guy, A.; Galano, J. M.; Durand, T.; Gil-Izquierdo, A. Impact of packaging atmosphere, storage and processing conditions on the generation of phytoprostanes as quality processing compounds in almond kernels. Food Chem. 2016, 211, 869-875.

(4) Imbusch, M. J.; Mueller, M. J. Formation of isoprostane F(2)-like compounds (phytoprostanes $\mathrm{F}(1)$ ) from alpha-linolenic acid in plants. Free Radical Biol. Med. 2000, 28, 720-726.

(5) Collado-González, J.; Moriana, A.; Girón, I. F.; Corell; Medina, S.; Durand, T.; Guy, A.; Galano, J. M.; Valero, E.; Garrigues, T.; Ferreres, F.; Moreno, F.; Torrecillas, A.; Gil-Izquierdo, A. The phytoprostane content in green table olives is influenced by Spanishstyle processing and regulated deficit irrigation. Food Sci. Technol. 2015, 64, 997-1003.

(6) Marhuenda, J.; Medina, S.; Díaz-Castro, A.; Martínez-Hernández, P.; Arina, S.; Zafrilla, P.; Mulero, J.; Oger, C.; Galano, J. M.; Durand, T.; Ferreres, F.; Gil-Izquierdo, A. Dependency of Phytoprostane Fingerprints of Must and Wine on Viticulture and Enological Processes. J. Agric. Food Chem. 2015, 63, 9022-9028.

(7) Carrasco-Del Amor, A. M.; Collado-González, J.; Aguayo, E.; Guy, A.; Galano, J. M.; Durand, T.; Gil-Izquierdo, A. Phytoprostanes in almonds: Identification, quantification, and impact of cultivar and type of cultivation. RSC Adv. 2015, 5, 51233-51241.

(8) Yonny, M. E.; Rodríguez Torresi, A.; Cuyamendous, C.; Réversat, G.; Oger, C.; Galano, J. M.; Durand, T.; Vigor, C.; Nazareno, M. A. Thermal stress in melon plants: phytoprostanes and phytofurans as oxidative stress biomarkers and the effect of antioxidant supplementation. J. Agric. Food Chem. 2016, 64, 8296-8304.

(9) Patterson, E.; Wall, R.; Fitzgerald, G. F.; Ross, R. P.; Stanton, C. Health implications of high dietary omega- 6 polyunsaturated fatty acids. J. Nutr. Metab. 2012, 2012, 1-16.

(10) Minghetti, L.; Salvi, R.; Lavinia-Salvatori, M.; Ajmone-Cat, M. A.; De Nuccio, C.; Visentin, S.; Bultel-Poncé, V.; Oger, C.; Guy, A.; Galano, J. M.; Greco, A.; Bernardo, A.; Durand, T. Non enzymatic oxygenated metabolites of $\alpha$-linolenic acid B1- and L1-phytoprostanes protect immature neurons from oxidant injury and promote differentiation of oligodendrocyte progenitors through PPAR- $\gamma$ activation. Free Radical Biol. Med. 2014, 73, 41-50.

(11) Cuyamendous, C.; Leung, K. S.; Durand, T.; Lee, J. C. Y.; Oger, C.; Galano, J. M. Synthesis and discovery of phytofurans: metabolites of $\alpha$-linolenic acid peroxidation. Chem. Commun. 2015, 51, 1569615699.

(12) Leung, K. S.; Chen, X.; Zhong, W.; Yu, A. C. H.; Lee, C. Y. J. Microbubble-mediated sonoporation amplified lipid peroxidation of Jurkat cells. Chem. Phys. Lipids 2014, 180, 53-60.

(13) Barden, A. E.; Croft, K. D.; Durand, T.; Guy, A.; Mueller, M. J.; Mori, T. A. Flaxeed Oil Supplementation Increases Plasma F1Phytoprostanes in Healthy Men. J. Nutr. 2009, 139, 1890-1895.

(14) Dupuy, A.; Le Faouder, P.; Vigor, C.; Galano, J. M.; Dray, C.; Lee, J. C.-Y.; Valet, P.; Gladine, C.; Durand, T.; Bertrand-Michel, J.; Oger, C. Simultaneous quantitative profiling of 20 isoprostanoids from omega- 3 and omega- 6 polyunsaturated fatty acids by LC-MS/MS in various biological samples. Anal. Chim. Acta 2016, 921, 46-58.

(15) Traidl-Hoffmann, C.; Kasche, A.; Mariani, V.; Jakob, T. Pollenassociated lipid mediators (PALMs): Pro-inflammatory and immunomodulatory activity on cells of the allergic inflammation. Allergo J. 2005, 14, 396-401.

(16) Parchmann, S.; Mueller, M. J. Evidence for the formation of dinorisoprostanes $\mathrm{E}_{1}$ from alpha-linolenic acid in plants. J. Biol. Chem. 1998, 273 (49), 32650-32655.
(17) Thoma, I.; Krischke, M.; Loeffler, C.; Mueller, M. J. The isoprostanoid pathway in plants: a review. Chem. Phys. Lipids 2004, $128,135-148$.

(18) Sasaki, T.; Burr, B. International rice genome sequencing. Project: The effort to completely sequence the rice genome. Curr. Opin. Plant Biol. 2000, 3, 138-142.

(19) Yang, Y.; Zhu, K.; Xia, H.; Chen, L.; Chen, K. Comparative proteomic analysis of indica and japonica rice varieties. Genet. Mol. Biol. 2014, 37 (4), 652-661.

(20) Juliano, B. O. Lipids in rice and rice processing. Lipids Cereal Technol. 1983, 305-330.

(21) El Fangour, S.; Guy, A.; Despres, V.; Vidal, J. P.; Rossi, J. C.; Durand, T. Total syntheses of the eight diastereoisomers of the synanti-synphytoprostanes F1 types I and II. J. Org. Chem. 2004, 69 (7), $2498-2503$.

(22) El Fangour, S.; Guy, A.; Vidal, J. P.; Rossi, J. C.; Durand, T. A flexible synthesis of the phytoprostanes B1 Type I and II. J. Org. Chem. 2005, 70 (3), 989-997.

(23) Pinot, E.; Guy, A.; Fournial, A.; Balas, L.; Rossi, J. C.; Durand, $\mathrm{T}$. Total synthesis of the four enantiomerically pure diasteroisomers of the phytoprostanes E1 Type II and of the 15- $\mathrm{E}_{2 \mathrm{t}}$-isoprostanes. J. Org. Chem. 2008, 73 (8), 3063-3069.

(24) Guy, A.; Flanagan, S.; Durand, T.; Oger, C.; Galano, J. M. Facile synthesis of cylopentenone B1- and L1-type phytoprostanes. Front. Chem. 2015, 3, 41 DOI: 10.3389/fchem.2015.00041.

(25) Cuyamendous, C.; Leung, K. S.; Bultel-Poncé, V.; Guy, A.; Durand, T.; Galano, J. M.; Lee, J. C.-Y.; Oger, C. Total Synthesis and in Vivo Quantitation of Phytofurans Derived from $\alpha$-Linolenic Acid. Eur. J. Org. Chem. 2017, 2017 (17), 2486-2490.

(26) Collado-González, J.; Medina, S.; Durand, T.; Guy, A.; Galano, J. M.; Torrecillas, A.; Ferreres, F.; Gil-Izquierdo, A. New UHPLCQqQ-MS/MS method for quantitative and qualitative determination of free phytoprostanes in foodstuffs of commercial olive and sunflower oils. Food Chem. 2015, 178, 212-220.

(27) Taber, D. F.; Morrow, J. D.; Roberts, L. J., II A nomenclature system for the isoprostanes. Prostaglandins 1997, 53, 63.

(28) Barbosa, M.; Collado-Gonzalez, J.; Andrade, P. B.; Ferreres, F.; Valentao, P.; Galano, J. M.; Durand, T.; Gil-Izquierdo, A. Nonenzymatic $\alpha$-Linolenic acid derivatives from the sea: Macroalgae as novel sources of phytoprostanes. J. Agric. Food Chem. 2015, 63, 64666474.

(29) Collado-González, J.; Girón-Moreno, I. F.; Medina-Escudero, S.; Galindo-Egea, A.; Ferreres, F.; Moreno-Lucas, F.; TorrecillasMelendreras, A.; Gil-Izquierdo, A. Effect of deficit irrigation and elaboration process of spanish-style green table olives on phytoprostanes content in Manzanilla de Sevilla olive flesh. Proceedings of XII Portuguese-Spanish Symposium on Plant Water Relations 2014, 19-23.

(30) Alasalvar, C.; Shahidi, F. Tree nuts: Composition, phytochemicals, and health effects; CRC Press, 2008; Vol. 17, p 340.

(31) Durakova, A. G.; Menkov, N. D. Moisture sorption characteristics of rice flour. Nahrung 2004, 48 (2), 137-140.

(32) Cuyamendous, C.; de la Torre, A.; Lee, Y. Y.; Leung, K. S.; Guy, A.; Bultel-Ponce, V.; Galano, J. M.; Lee, J. C. Y.; Oger, C.; Durand, T. The novelty of phytofurans, isofurans, dihomo-isofurans and neurofurans: Discovery, synthesis and potential application: a review. Biochimie 2016, 130, 49-62.

(33) Brown, M. A.; Storlien, L. H.; Huang, X.; Tapsell, L. C.; Else, P. L.; Higgins, J. A.; Brown, I. L. Dietary fat and carbohydrate composition: Metabolic disease. In: Fat detection: taste, texture, and post ingestive effects; Montmayeur, J. P., Ed.; CRC Press/Taylor \& Francis, 2010; Chapter 21.

(34) Seetharamaiah, G. S.; Chandrasekhara, N. Studies on hypocholesterolemic activity of rice bran oil. Atherosclerosis 1989, 78, 219-223.

(35) Morrison, W. R. Starch lipids and how they relate to starch granule structure and functionality. Cereal Foods World 1995, 40, 437446. 
(36) Liu, L.; Waters, D. L. E.; Rose, T. J.; Bao, J.; King, G. J. Phospholipids in rice: significance in grain quality and health benefits: a review. Food Chem. 2013, 139, 1133-1145.

(37) Thoma, I.; Loeffler, C.; Sinha, A. K.; Gupta, M.; Krischke, M.; Steffan, B.; Roitsch, T.; Mueller, M. J. Cyclopentenone isoprostanes induced by reactive oxygen species trigger defense gene activation and phytoalexin accumulation in plants. Plant J. 2003, 34 (3), 363-75.

(38) Fessel, J. P.; Porter, N. A.; Moore, K. P.; Sheller, J. R; Roberts, L. J. Discovery of lipid peroxidation tetrahydrofuran ring (isofurans) that are favored by increased oxygen tension. Proc. Natl. Acad. Sci. U. S. A. 2002, 99, 16713-16718. 